${ }^{1}$ Department of Health Education \& health promotion, Faculty of Medical Sciences, Tarbiat Modares University
Corresponding author:

Fatemeh Zarei

Department of Health education and Health Promotion, Faculty of Medical Sciences, Tarbiat Modares University, Tehran, Iran.

Email:f.zarei@modares.ac.ir

Received: April 16, 2019

Accepted: September 10, 2019

\section{Comparison of peer led and teacher led oral health educational program among students}

\author{
Afsaneh Karami ${ }^{1}$, Alireza Heidarnia ${ }^{1}$, Fatemeh Zarei ${ }^{1, *}$
}

Aim: The purpose of this study was to determine the impact of Peer-Led Education (PLE)comparing with the Teacher-led education(TLE) approach about oral health behavior of female school- student aged at 6-12 in district 6 of Tehran, Iran. Methods: This is a quasi-experimental study. Two primary public schools in Tehran district 6, were selected by simple random sampling and from each school one class considered for PLE and TLE. 120 fourth grade female students of the 6th district of Tehran were enrolled for study. All participants were assessed about knowledge, attitude, and practice in oral health by Pre-test one month before the intervention program. A valid questionnaire in Persin version used for data gathering. Two representatives including teacher and students from both groups trained under the supervision of a health educator. In PLE each of the six students trained 10 other students in the middle of the day per three consecutive sessions. In TLE one teacher trained one class with about 30 students. Both education program set up at the same time and duration. The educational materials included educational short films, animation, and booklet powered driven by Oral Health Burea, Iran health ministry. Apart from, the intervention included role play and storytelling too. The evaluation had done by post-test with the same tool one month later after the intervention. Results: The average mean score of the knowledge, attitude, and practice in both group after educational intervention significantly increased $(P<0.05)$. The mean score of knowledge, attitude, and practice in PLE have been effective than TLE. Conclusion: Health education with peer education approach is effective in improving oral health behavior in children at school age.

Keywords: Oral health. Health education. Peer education. 


\section{Introduction}

Oral hygiene is one of the important branches of public health that has a noteworthy impact on the health of the people? ${ }^{1}$ The World Health Organization (WHO) considers oral health as a necessity and part of overall health throughout life, saying that poor oral health and oral untreated diseases can have a profound impact on quality of life $^{2}$. One of the most common chronic diseases of oral health is tooth decay, which is a major health problem in most countries of the world, especially in developing countries $^{3}$. Despite the importance of oral and dental hygiene among children and adolescents, we continue to see the prevalence of dental caries among them ${ }^{4}$. Oral diseases can lead to irreversible injuries and consequences such as pain, depression, decreased self-esteem, low quality of life, acute and chronic infections, and so on. In addition, oral and dental illness can restrict individual activities at school, at work, or at home, causing millions of hours to die every year around the world 5 . One of the goals of the World Health Organization for oral health is that the DMFT (the number of stuffed, rotten or drawn teeth) should reach less than one ${ }^{6}$. Evaluation of DMFT in students of Yazd in 2012, this amount is estimated at 7.17. Also, according to the World Health Organization DMFT index for 12-year-old children in America 8/2, 6/2 in Europe and in Africa is 3.1.In Iran, the average of this index is $1.7^{3}$.

Nutritional behaviors in children such as high consumption of sugar, lack of dairy consumption, unfulfilled habits, such as the tendency to brush and use floss, increase the prevalence of caries in these children ${ }^{8}$. In this regard, the findings indicate that the health of oral and dental tissues of the population is related to the level of knowledge and information about oral hygiene behaviors ${ }^{9}$. Effective techniques for the prevention of dental caries and periodontal diseases include self-care oral health (using dental floss and brushing) and fluoride therapy ${ }^{10}$. In order to change habits, interventions in the field of health education are essential. In this regard, Sattel believes health education is an essential element in the advancement of health, and one of its important roles is to prepare the people of the community through knowledge and information to them, and to demonstrate their skills and health practices ${ }^{11}$. The age group of $12-6$ years old is one of the priority groups of oral health programs due to the high prevalence of tooth decay and the valuable position of age in terms of the development of permanent teeth on the one hand and the formation of beliefs, habits, and lifestyle on the other hand. Any change or improvement in the health behavior of this group can have a lasting and significant impact on the health of the future generation of the community ${ }^{12}$. Meanwhile, the school is the easiest and most cost-effective way to reach this age group ${ }^{13}$.

One of the approaches used in teaching is the child- to-child education approach. The original idea of this approach was presented in 1978 by Hove Hawz and Morley. The program has been officially launched since 1979 (World Children's Year), and since then many countries, including Iran, have implemented the program. The main feature of the child-child approach is the involvement of children directly in the education process and promoting health ${ }^{14}$.

Innovative methods to education for health are essential to gain the benefits. Child to child approach education method is a new way of providing health education to 
school children and the use of this method maximizes the spread of health messages ${ }^{1}$. It is an active method that encourages learning by easy manner. The child has the power to spread the health messages, therefore, this method links what is educated in school room with what to do out of the class and at home. A child passing health messages to younger brothers and sisters, friends and so jointly collaborating to become a positive power for health ${ }^{15}$.

Considering the necessity of prevention of oral and dental illness in students, and the weakness of the results of the current training peer-led education (PLE), we aimed to use the alternative peer-led education to make it effective approach. Therefore, the present study designed to determine the effectiveness of PLE approach in comparison with the teacher-led education (TLE) approach in the field of oral and dental care in primary school girls in district 6 of Tehran.

\section{Materials and method}

\section{Study design and eligibility criteria}

The study was a quasi-experimental study that will be conducted on 120 female primary schoolchildren from two elementary schools in Tehran's District 6 in 2018. The study conducted before and after interventions with two interventional groups, including PLE and TLE. The inclusion criteria were studying at grade 4, living in Tehran, willingness to participate in the study and the parents, satisfaction. The following flow diagram shows the methodology design in brief (Figure 1).

\section{Sampling}

The study samples were elementary school students who were selected from two public schools in the 6th district of Tehran and randomly divided into two groups of intervention, including peer education and classroom education (coaching assistance). Regarding the mean and standard deviation in the two groups based on the previous studies ${ }^{16}$ and considering confidence level of $95 \%$ and the test power of $80 \%$ the sample size of 46 students were achieved in each group and with considering an excess number of study sample due to withdrawal (missing) about 60 students were chosen to participate in each study group.

The two schools were randomly selected from the list of all public schools in District 6 In total, 120 students at fourth-grade are selected to participate in the study and will be measured before and one month after the intervention. From each school, a class of 30 is selected as PLE and another class as TLE. In PLE group 30 students in the 10-member group received educational intervention from 3 trained student who was at fifth-grade.

\section{Instrument}

Data were collected through a standard questionnaire in Persian ${ }^{17}$ including four sections: demographic information, knowledge, attitude, and behavior before and after the intervention. Demographic questions included age, residency, parenting, parenting. Students' attitudes are measured according to the 5-Likert scale,i.e. completely 


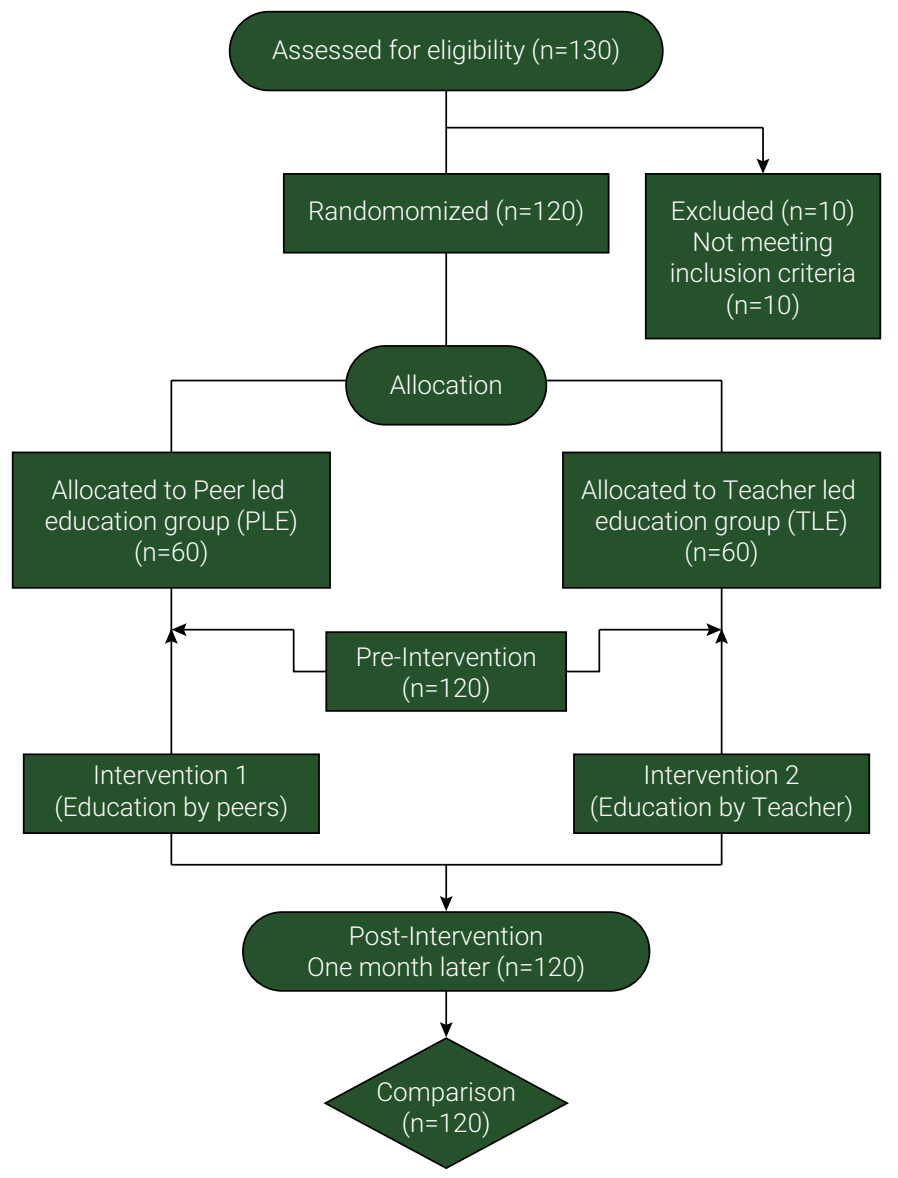

Figure 1. Flow diagram of methodology design

agree, agree, uncertain, disagree, and completely disagree. The questionnaire Validity and validity were confirmed. The questionnaire validity was checked by 10 experts in health promotion fields and the content validity was evaluated by two indexes of CVR and CVI that were $0.90 \%$ and $0.85 \%$, respectively. To determine the questionnaire reliability, test-re-test and the Cronbach's alpha coefficient were calculated and Cronbach's alpha was calculated to be 0.76 .

\section{Pre-test before intervention}

At the entrance to each of the primary and before completing the questionnaires, the study goals and objectives will be explained. The questionnaires will be distributed and explained on how to complete them. The completed anonymous questionnaires were remarked by code by the students themselves to ensure them that data was collected confidentially.

\section{Development and implementation of training program}

According to the results obtained in the pre-test and the needs assessment that was done based on the objectives of the study, training programs are prepared for the 
two groups. Training will be provided through educational pamphlets, posters and 10-minute animations, and practical training for brushing and flossing. It should be noted that all the materials (educational content) used in both PLE and TLE groups are accurately trained by the health educator. Apart from, all educational contents were powered driven by Oral Health Burea, Iran ministry of health.

\section{Evaluation of training program}

To evaluate the educational programs, the study groups will be assessed in two different time periods, before and one month after the educational intervention through a questionnaire.

\section{Data analysis}

the data analysis was conducted using SPSS software to assess the impact of peer education and classroom education. The descriptive statistics (such as means, standard deviation, and frequency tables) and Chi-Squire (for demographic variables) were used. To analyze the data, before and after the interventions, ANKOVA were performed using SPSS version 18 (SPSS Inc., Chicago, Illinois, USA). The significance level was set at $p<0.05$.

\section{Ethics of research}

This study approved by an ethical code (IR.TMU.REC.1396.665). In this study participation is voluntary and the students participate in the study with consent. The study objectives are explained to students and their parents, teachers, educational authorities, and schools' administrators. During the educational programs, the authors tried to avoid any interruption on the student's classes.

\section{Results}

According to the finding 120, fourth-grade students from two schools with an average age of 10 years were enrolled in the study. Demographic variables include student's age, father's job, father education level, mother's job, mother education level. The results showed that none of the demographic variables, except the father's job $(P=0.039)$, were significantly different between the two groups of Teacher Led and Peer-Led Education. (Table 1)

According to Table 2, the mean score of Knowledge after intervention in the education group by the Teacher (TLE) and the education group by peers (PLE) and also in the groups with different father's job were not significant $(p>0.05)$. Furthermore, the score of knowledge in different groups has not the same effect. $(P<0.05)$. (Table 2$)$

According to the Partial Eta Squared, group covers $1.8 \%$ of Knowledge chenges in post test, $0.7 \%$ of the father's job, and $6.7 \%$ of Knowledge chenges in pre-test. (Table 3 )

According to Table 4, the mean score of attitude after intervention in the education group by the Teacher (TLE) and the education group by peers(PLE) was significant $(p<0.05)$. There was no signifact meaning in the groups with different father's job $(p>0.05)$. Furthermore, the score of attitude in different groups has not the same effect $(P<0.05)$. (Table 4) 
Table 1. Demographic variables between the two groups of PLE and TLE

\begin{tabular}{|c|c|c|c|c|}
\hline & & $\begin{array}{c}\text { Teacher- led } \\
\text { N (\%) }\end{array}$ & $\begin{array}{c}\text { Peer -led } \\
\text { N (\%) }\end{array}$ & P-value \\
\hline \multirow{2}{*}{ Age } & 9 & $6(10)$ & $2(3.3)$ & 0.136 \\
\hline & 10 & $54(90)$ & $58(96.7)$ & \\
\hline \multirow{3}{*}{ Mother education level } & Under the diploma & $18(30)$ & 19 (31.7) & \multirow{3}{*}{0.650} \\
\hline & Diploma & $6(10)$ & $9(15)$ & \\
\hline & Academic & $36(60)$ & $32(53.3)$ & \\
\hline \multirow{3}{*}{ Father education level } & Under the diploma & 9 (15.5) & $6(10.2)$ & \multirow{3}{*}{0.244} \\
\hline & Diploma & $12(2.07)$ & $20(33.9)$ & \\
\hline & Academic & $37(63.8)$ & $33(55.9)$ & \\
\hline \multirow{4}{*}{ Mother's job } & Housekeeper & $22(36.7)$ & $28(46.7)$ & \multirow{4}{*}{0.528} \\
\hline & Employee & $25(41.7)$ & $18(30)$ & \\
\hline & Unemployment & $7(11.7)$ & $6(10)$ & \\
\hline & Others & $6(10)$ & $8(13.3)$ & \\
\hline \multirow{4}{*}{ Father's job } & worker & $3(5)$ & $5(8.3)$ & \multirow{4}{*}{0.039} \\
\hline & Employee & $28(46.7)$ & $16(26.7)$ & \\
\hline & Unemployment & $19(31.7)$ & $17(28.3)$ & \\
\hline & Others & $10(16.7)$ & $22(36.7)$ & \\
\hline
\end{tabular}

Table 2. Analysis of Covariance for the Effect of education on knowledge

\begin{tabular}{lccccc}
\hline Source & df & SS & MS & F & Partial Eta Squared \\
\hline Group & 1 & 7.540 & 7.540 & 2.116 & 0.018 \\
\hline Father's Job & 3 & 2.852 & 0.951 & 0.267 & 0.007 \\
\hline knowledg & 1 & 29.317 & 29.317 & ${ }^{*} 8.227$ & 0.067 \\
\hline Error & 114 & 406.241 & 3.564 & & \\
\hline Total & 119 & 440.992 & & & \\
\hline & $* \star P<0.01$ & & & \\
\hline
\end{tabular}

Table 3. The mean and standard deviation of the knowledge scores after intervention in terms of education type and Father's Job

\begin{tabular}{lcccc}
\hline \multirow{2}{*}{ Father's Job } & \multicolumn{2}{c}{ TLE } & \multicolumn{2}{c}{ PLE } \\
\cline { 2 - 5 } & $\mathbf{M}$ & $\mathbf{S D}$ & $\mathbf{M}$ & $\mathbf{S D}$ \\
\hline worker & 7.33 & 2.31 & 7.80 & .45 \\
\hline Employee & 7.46 & 1.48 & 7.00 & 1.46 \\
\hline Unemployment & 7.21 & 2.18 & 6.71 & 2.87 \\
\hline Others & 6.90 & 1.20 & 7.68 & 2.12 \\
\hline Total & 7.28 & 1.70 & 7.23 & 2.14 \\
\hline
\end{tabular}

According to the Partial Eta Squared, group covers $22.0 \%$ of attitude chenges in post test, $0.4 \%$ of the father's job, and $7.0 \%$ of attitude chenges in pre-test. (Table 5 )

According to Table 6, the mean score of practice after intervention in the education group by the Teacher (TLE) and the education group by peers (PLE) was significant $(p<0.05)$. 
There was no signifact meaning in the groups with different father's job ( $p>0.05)$. Furthermore, the score of practice in different groups has not the same effect $(P<0.05)$. (Table 6) According to the Partial Eta Squared, group covers 11.3\% of practice chenges in post test, $0.8 \%$ of the father's job, and $3.4 \%$ of practice chenges in pre-test. (Table 7 )

Table 4. Analysis of Covariance for the Effect of education on Attitude

\begin{tabular}{lccccc}
\hline Source & df & SS & MS & F & Partial Eta Squared \\
\hline Group & 1 & 550.310 & 550.310 & ${ }^{* *} 32.074$ & 0.220 \\
\hline Father's Job & 3 & 8.086 & 2.695 & 0.157 & 0.004 \\
\hline Attitude & 1 & 148.103 & 148.103 & ${ }^{* *} 8.632$ & 0.070 \\
\hline Error & 114 & 1955.939 & 17.157 & & \\
\hline Total & 119 & 2603.967 & & & \\
\hline & $* * P<0.01$ & & \\
\hline
\end{tabular}

Table 5. The mean and standard deviation of attitude scores after intervention in terms of education type and father's job

\begin{tabular}{lcccc}
\hline \multirow{2}{*}{ Father's Job } & \multicolumn{2}{c}{ TLE } & \multicolumn{2}{c}{ PLE } \\
\cline { 2 - 5 } & $\mathbf{M}$ & SD & $\mathbf{M}$ & SD \\
\hline worker & 30.67 & 8.08 & 34.80 & 2.59 \\
\hline Employee & 30.96 & 4.60 & 34.94 & 3.11 \\
\hline Unemployment & 30.63 & 5.48 & 34.47 & 4.32 \\
\hline Others & 30.60 & 4.50 & 35.09 & 3.15 \\
\hline Total & 30.78 & 4.92 & 34.85 & 3.40 \\
\hline
\end{tabular}

Table 6. Analysis of Covariance for the Effect of education on Practice

\begin{tabular}{lccccc}
\hline Source & Df & SS & MS & F & Partial Eta Squared \\
\hline Group & 1 & 31.697 & 31.697 & ${ }^{* *} 14.518$ & 0.113 \\
\hline Father's Job & 3 & 2.001 & 0.667 & 0.306 & 0.008 \\
\hline Practice & 1 & 8.839 & 8.839 & $4.049^{*}$ & 0.034 \\
\hline Error & 114 & 248.905 & 2.183 & & \\
\hline Total & 119 & 290.667 & & & \\
\hline
\end{tabular}

Table 7. The mean and standard deviation of the practice scores after intervention in terms of education type and father's job.

\begin{tabular}{lcccc}
\hline \multirow{2}{*}{ Father's Job } & \multicolumn{2}{c}{ TLE } & \multicolumn{2}{c}{ PLE } \\
\cline { 2 - 5 } & $\mathbf{M}$ & $\mathbf{S D}$ & $\mathbf{M}$ & $\mathbf{S D}$ \\
\hline worker & 2.67 & .58 & 2.60 & .55 \\
\hline Employee & 2.18 & 1.63 & 2.94 & 1.48 \\
\hline Unemployment & 2.21 & 1.90 & 3.18 & 1.13 \\
\hline Others & 1.80 & 1.48 & 3.50 & 1.37 \\
\hline Total & 2.15 & 1.64 & 3.18 & 1.30 \\
\hline
\end{tabular}




\section{Discussion}

The effectiveness of peer education approach is based on the theory that reveal sensitive information will be transmitted more easily between people of the same situation $^{16}$. In this regard, the present study aimed to compare two methods included Peer-Led Education (PLE) and Teacher-Led Education (TLE) on improving oral health behaviors of Iranian female students.

The findings indicated that the knowledge was increased in both TLE and PLE groups but the comparison of the difference between the mean score of knowledge before and after the intervention between TLE and PLE indicated that the level of knowledg increased differently. In other words, PLE was more effective than TLE to increase the knowledge about oral health among participants. This finding was confirmed by other similar studies ${ }^{17}$. The study of Najjar Lashgari et al. ${ }^{16}$ (2013) revealed that a child-to-child education had been effective on improving the health awareness in students. In more clarification, the education by peer groups not only adds to student's awareness, but also health behaviour would be eased for any cognitive changes ${ }^{18}$. To our knowledg, some studies do not confirm effects of child-to-child education or peer education posetivley. In line with this, Moeini et al. ${ }^{19}$ (2013) proved that there was no significant difference in the knowledge, attitude, and practice levels after educational intervention which adressed the Child coach and Teacher coach group ${ }^{19}$. Along with this study, Kargar et al. ${ }^{20}$ (2013) concluded that there was no significant difference between the peers and adults-led education program before, immediately and one month later ${ }^{20}$.

In our study Low growth in knowledge after intervention among students who coached with peer might be due to the lack of information of fellows. Apart from the knowledge level of a peer, characteristically it seems that, choosing a proper educator as a fellow is another considerable point in this type of educational program. The peer students should have autonomy and be acceptable to other students and should be explaining the lesson that have learned to other students appropriately. However, according to the results of the current study the level of student's knowledge who trained as peers were increased after post-intervention. It may be due to peer accountability and emphasis on the most frequently asked questions by students. In this matter, peer educators seemed to be more effective and successful than the TLE because of their familiarity with the needs of the target group.

In the present study, our findings indicated that the attitude was increased in both TLE and PLE groups. The results showed that the difference in mean score of attitude between both groups before and after the intervention was also significant $(P<0.005)$.

Therefore education by peers had a greater impact on students' attitudes than education by teachers. Several studies indicated that peer-led educational programs have had a greater impact on children's attitude and understanding of health issues compared to children who did not recived these programs ${ }^{21}$. In the study of Akbarzadeh et al. ${ }^{22}$ (2009), the attitudes of trained students by peer groups after intervention improved compared to health staff which represents the effect of education by peers ${ }^{22}$. Moreover, in the study of Noorisistani et al. ${ }^{23}$ (2010), there was a significant 
difference between the mean scores of attitude in two groups of peers and the lecture-based education on attitude improvement in health issues ${ }^{23}$.

Regarding the significance of the difference in attitude before and after intervention in peer group, it seems that there were some reasons to belive why a Peer-led educational program was more effective and succsessful method for health education among students. The way of communicating with students, as an acceptable and believable role model, the simplicity in explanning for the educational contents, are some of these effective reasons to greatly influence on changing the attitude.

In this study, the students' practice in brushing, dental floss, using mouthwash and regular referral to the dentist significantly has been increased before and after the education in the peer- led and the teacher-led. Furthuremore, the mean performance score for oral health behaviors before training between the two groups was statistically significant $(p<0.05)$.

However, this difference after training was significant between the two groups $(P<0.05)$ Perhaps the conclusion can be interpreted that students who have a high level of knowledge and attitude in the field of oral health behaviour have a better performance than the others. This result was confirmed in several studies, including Kaveh et al. in $2016^{24}$ and Leana and D'Souza in $2017^{25}$. A study by Walvekar et al showed that the child-to-child education program had a significant impact on increasing knowledge, changing in attitude and behaviors in relation to diarrhea in students in child-to-child group compared to the control group ${ }^{26}$; In contrast, Kaveh et al, showed that there was no significant difference in the mean scores of nutritional behaviors in the control group ${ }^{24}$. Additionally, Tolli27 (2012) concluded that there was no evidence of the effectiveness of the peer education method in relation to the desired behaviors in peer groups compared to the control group ${ }^{27}$.

In general, the results of this study showed that the peer group's approach to improving the knowledge, attitude and oral health behaviors was more successful than teacher-led education,by adjusting the father's job variable.to put it simple, the oral health behavior including the knowledge, attitude and practice after intervention is affected by both the father's job and also the type of education approach. Therefore, due to the serious shortage of health educators in the country's schools, proper planning and holding of better and longer-term training courses for students can fill up the vacancies of health education in schools. For an effective oral health education addressing school student age group, as well as Peer-led educational program, is suggested to be used in the oral health promotion program.

\section{Strengths and limitations}

Despite all the strong points of the present research, it had some limitations; firstly, the outcomes were evaluated only for one month after the educational intervention. Thus, future studies with longer follow- up periods are recommended to be conducted for better evaluation. In addition, the final evaluation in this study was based on the students self-reports, which could result in bias. Hence, future studies can use a combination of self-report, direct observation of the behavior, and report by parents. As a final limitation. For the present study, the short duration of follow-up sessions can be noted. This was due to the time limitations of the research. 


\section{Acknowledgments}

This article was derived from MSc thesis and financially supported by Tarbiat Modares University

\section{Competing interests}

\section{None of the authors have any conflict of interest.}

\section{References}

1. Naghibi SA, Yazdani Cherati J, Khujeh Z, Shah Hosseini M. Factors influencing oral health behavior according to BASNEF Model. J Mazandaran Univ Med Sci. 2013;23(99):76-83.

2. Badri Gargari R, N. SH. The role of factors related to perceived self efficacy and health behavior brushing and flossing pull the visitors to the private office of Tabriz. Int J Res Med Sci. 2011;9(3):130-8.

3. Fallahi A, Morowatisharifabad M. Between tooth cleaning behaviors of the transtheoretical model-based pre-university student-ts in Yazd. Tehran Uni Med Sci J. 2010;4:45-8.

4. Kwan S, Petersen PE, Pine CM, Borutta A. Health-promoting schools: an opportunity for oral health promotion. Bull World Health Organ. 2005 Sep;83(9):677-85.

5. Ciancio S. Improving oral health: current considerations. J Clin Periodontol. 2003;30 Suppl 5:4-6

6. Asif M, Shobha KS, Anirban C. Assessment of efficacy of different teaching methods of tooth brushing on oral hygiene stutus in adults. J Health Sci Res. 2017 May;1(8):25-30. doi: 10.5005/jp-journals-10042-1044.

7. Arora A, Scott JA, Bhole S, Do L, Schwarz E, Blinkhorn AS. Early childhood feeding practices and dental caries in preschool children: a multi-centre birth cohort study. BMC Public Health. 2011 Jan 12;11:28. doi: 10.1186/1471-2458-11-28.

8. Amalia R, Schaub RM, Widyanti N, Stewart R, Groothoff JW. The role of schoolbased dental programme on dental caries experience in Yogyakarta Province, Indonesia. Int J Paediatr Dent. 2012 May;22(3):203-10. doi: 10.1111/j.1365-263X.2011.01177.x.

9. Petersen PE. Global policy for improvement of oral health in the 21 st century-implications to oral health research of World Health Assembly 2007, World Health Organization. Community Dent Oral Epidemiol. 2009 Feb;37(1):1-8. doi: 10.1111/j.1600-0528.2008.00448.x.

10. Nyvad B. Cariology in the 21st century. State of the art and future perspectives. Caries Res. 2004May-Jun;38(3):170.

11. Goodarzi, A., Heidarnia, A., Tavafian, S. S., \& Eslami, M. (2018). Evaluation of Decayed, Missing and Filled Teeth (DMFT) index in the 12 Years Old Students of Tehran City, Iran. Brazilian Journal of Oral Sciences, 17, e18888. https://doi.org/10.20396/bjos.v17i0.8654061

12. Watt RG. Emerging theories into the social determinants of health: implications for oral health promotion. Community Dent Oral Epidemiol. 2002 Aug;30(4):241-7.

13. Locker D, Matear D, Stephens M, Jokovic A. Oral health-related quality of life of a population of medically compromised elderly people. Community Dent Health. 2002 Jun;19(2):90-7.

14. Speizer I, Magnani RJ, Colvin CE. The effectiveness of adolescent reproductive health interventions in developing countries: a review of the evidence. J Adolesc Health. 2003 Nov;33(5):324-48.

15. Lotfi Mainbolagh B, Rakhshani F, Zareban I, Montazerifar F, Sivaki HA, Parvizi Z. The effect of peer education based on health belief model on nutrition behaviors in primary school boys. J Res Health Soc Devel Health Prom Res Center. 2012;2(2):214-25. 
16. Najjar Lashgari S, Rahim Aghaee F, Dehghan Nayeri N. The effect of child to child education on health awareness of third grade female students in primary school. Modern Care Journal. 2013; 10(2):132-40.

17. Karimzadeheshirazi K, Heydarnia A. [Child to Child's help: a New approaches to health education]. Armaghanedanesh. J Yasuj Univ Med Sci. 2000;5(17-18):28-35. Persian.

18. Farrokhmanesh M, Mokhtari Lakeh N, Asiri S, Kazem Nezhad Leyli E, Ghaemi A, Afzali S. A Comparative Effect of Child-to-Child and Health Educator to-Child Teaching Approaches on Nutritional Status in Elementary School Students. J Holistic Nurs Midwifery. 2018;28(2):101-8.

19. Moeini B, Ghaderi A, Hazavehei S, Allahverdipour H, Moghimbeigi A, Jalilian F. [A comparative study of peer education and Trainer education on the basis of health belief model(HBM) In improving oral health in Snandaj boy's elementary school]. Toloo-e-Behdasht. 2013 Summer;12(2):1-13. Persian.

20. Kargar M, Jamali Moghadam N, Moattari M. The effect of osteoporosis prevention education by peers and health personnel on self-efficacy of adolescents with nephrotic syndrome. Iran J Nurs. 2013;26(81):44-53.

21. Krones T, Keller H, Becker A, Sönnichsen A, Baum E, Donner-Banzhoff N. The theory of planned behaviour in a randomized trial of a decision aid on cardiovascular risk prevention. Patient Educ Couns. 2010 Feb;78(2):169-76. doi: 10.1016/j.pec.2009.06.010.

22. Akbarzadeh $M$, Zangiabadi M, Moattari M, Tabatabaei $H$. Comparing the effect of teaching breast self-examination by peers and health care personnel on students knowledge and attitude. Iranian J Med Educ. 2009;8(2):195-203.

23. Noorisistani M, Khoei EM, Taghdisi MH. T. Promoting knowledge, attitude and practices (KAP) of the mothers in their Girls' pubertal health based on peer education approach. J Babol Univ Med Sci. 2010 Feb;11(6):33-9.

24. Kaveh MH, Nejad ZK, Nazari M, Ghaem H. Evaluating the effect of the child-to-child approach based on the Theory of Planned Behavior on the eating behaviors of elementary school students. Int J Med Res Health Sci. 2016;5(5):121-6.

25. Leena KC, D'Souza J. Effectiveness of child to child approach to health education on prevention of worm infestation among children of selected primary schools in Mangalore. Nitte Univ J Health Sci. 2014 Mar;4(1):113-5.

26. Walvekar PR, Naik V, Wantamutte AS, Mallapur MD. Impact of child to child programme on knowledge, attitude practice regarding diarrhoea among rural school children. Indian J Community Med. 2006 Jan;31(2):56-9.

27. Tolli MV. Effectiveness of peer education interventions for HIV prevention, adolescent pregnancy prevention and sexual health promotion for young people: a systematic review of European studies. Health Educ Res. 2012 Oct;27(5):904-13. doi: 10.1093/her/cys055. 